\title{
The effects of regular consumption of short-chain fructo-oligosaccharides on digestive comfort of subjects with minor functional bowel disorders
}

\author{
Damien Paineau ${ }^{1}$, Flore Payen ${ }^{1}$, Suzanne Panserieu ${ }^{2}$, Geneviève Coulombier ${ }^{3}$, Annie Sobaszek ${ }^{4}$, \\ Isabelle Lartigau ${ }^{4}$, Marylène Brabet ${ }^{5}$, Jean-Paul Galmiche ${ }^{6}$, Dominique Tripodi ${ }^{6}$, Sylvie Sacher-Huvelin ${ }^{6}$,
} Véronique Chapalain ${ }^{7}$, Othar Zourabichvili ${ }^{1}$, Frédérique Respondek ${ }^{8 *}$, Anne Wagner ${ }^{8}$ and Francis R. J. Bornet ${ }^{1}$

${ }^{1}$ Nutri-Health SA, Immeuble Ampère, 8 rue Eugène et Armand Peugeot, 92566 Rueil-Malmaison Cedex, France

${ }^{2}$ Department of Occupational Medicine, Hôpital Avicenne, 125 route de Stalingrad, 93009 Bobigny, France

${ }^{3}$ Department of Occupational Medicine, CHU de Poitiers, 2 rue de la Milétrie, 86000 Poitiers, France

${ }^{4}$ Department of Occupational Medicine, CHU Claude Huriez, rue Michel Polonovski, 59037 Lille, France

${ }^{5}$ Department of Occupational Medicine, CHU St-Eloi, 80 Avenue Augustin Fliche, 34295 Montpellier Cedex 5, France

${ }^{6}$ Departments of Occupational Medicine and Gastroenterology, CHU Hôtel-Dieu Nantes, 1 place Alexis Ricordeau, 44093 Nantes Cedex 01, France

${ }^{7}$ Quanta Medical, Immeuble Ampère, 8 rue Eugène et Armand Peugeot, 92566 Rueil-Malmaison Cedex, France

${ }^{8}$ Béghin Meiji, Z.I. et Portuaire, B.P. 32, 67390 Marckolsheim, France

(Received 3 January 2007 - Revised 29 May 2007 - Accepted 13 June 2007)

A comparative, randomised, double-blind trial was performed in the medical departments of five hospitals to study the effects of regular consumption of short-chain fructo-oligosaccharides (sc-FOS) on the digestive comfort of subjects with minor functional bowel disorders (FBD). In step 1, 2235 subjects were questioned to assess the incidence and intensity of digestive disorders. In step 2, 105 of these patients diagnosed with minor FBD were randomised into two groups to receive either $5 \mathrm{~g}$ sc-FOS or $5 \mathrm{~g}$ placebo (sucrose and maltodextrins) per $\mathrm{d}$ over a 6-week period. The incidence and intensity of digestive disorders were assessed at the end of the treatment period (day 43) using the step 1 questionnaires. A qualityof-life questionnaire was also completed at the start and end of the treatment period to assess potential effects on well-being and social performance. In step 1, $44 \%$ of the subjects questioned presented FBD, of whom $57.1 \%$ suffered from minor FBD. In step 2, on day 43, the intensity of digestive disorders decreased by $43.6 \%$ in the sc-FOS group $v$. a $13.8 \%$ increase in the placebo group $(P=0.026)$. Symptoms were experienced less frequently by $75.0 \%$ of subjects in the sc-FOS group, while $53.8 \%$ of controls experienced no change $(P=0.064)$. Using the functional digestive disorders quality of life questionnaire, the discomfort item scores increased in the sc-FOS group $(P=0.031)$. However, expressed as change in quality of life (improvement, worsening or unchanged), daily activities were significantly improved in the sc-FOS group $(P=0.022)$. Regular consumption of sc-FOS may improve digestive comfort in a working population not undergoing medical treatment.

Short-chain fructo-oligosaccharides: Quality of life: Functional bowel disorders

Functional bowel disorders (FBD) are diagnosed on the basis of characteristic symptoms in the digestive system persisting for at least 12 weeks over the last 12 months in the absence of any structural or biochemical explanation ${ }^{1}$. The five main symptoms reported by patients are abdominal bloating, rumbling, transit disorders (occasional constipation and/or diarrhoea, possibly alternating), abdominal pains and flatulence. FBD have been reported as being chronic, non-life-threatening conditions, but having a marked impact on daily activities, wellbeing and social performance, even during symptom-free periods, mainly due to apprehension about impending pain ${ }^{2-6}$.

These functional disorders, influenced by psychological and environmental factors ${ }^{7}$, are common, with a reported prevalence of up to $61 \%$ in the French population aged over 15 years $^{6}$. Functional disorders thus lead to a high number of general medical and gastroenterology consultations, respectively accounting for 10 and $50 \%$ of all medical consultations ${ }^{4-6,8-11}$. However, two-thirds of subjects with FBD never consult a doctor for their disorder. A nutritional approach therefore appears a good alternative to medication for subjects with minor FBD or individuals rejecting medical therapy. Amongst the few already well-established ingredients recognised as having an impact on the digestive system, shortchain fructo-oligosaccharides (sc-FOS) are known to be fully fermented by the colonic microflora and, above all, to increase colonic bifidobacteria ${ }^{12-15}$ recognised as health 
promoting ${ }^{16,17}$. Sc-FOS occur in numerous edible plants such as onions, garlic, asparagus, tomatoes and wheat. Bacterial fermentation of sc-FOS increases production of SCFA such as acetate, propionate and butyrate ${ }^{18,19}$, whose ability to regulate ileal motility has been demonstrated by several studies $^{20-22}$. As described by Hidaka ${ }^{17}$, sc-FOS improve intestinal function with greater consistency and regularity in stool output.

Thus, while their impact on colonic health has been widely studied, little is as yet known about the impact of sc-FOS on the quality of life of subjects with FBD.

The present study was designed to test the efficacy of sc-FOS in improving digestive comfort among subjects with minor FBD.

\section{Subjects and methods}

Subjects

Subjects were recruited in the occupational medicine departments of five hospitals.

An initial questionnaire designed to assess the incidence and intensity of digestive disorders as well as the number of subjects presenting FBD was completed by 2235 subjects (Fig. 1).

This questionnaire was then analysed by a doctor at each study centre. Of the 2235 patients, 983 were presenting digestive disorders, of whom $57.1 \%$ had minor symptoms. A total of 186 subjects met all of the following inclusion criteria: age $>18$ years, presenting at least two minor FBD symptoms according to the Rome II criteria ${ }^{23}$ for at least 12 weeks over the last 12 months, a total intensity score of $\leq 25$ for the symptoms included in the initial questionnaire, an intensity score of $\leq 5$ for 'discomfort or abdominal pain', as well as relief following defecation, no major digestive disease and no previous consultation or medication for FBD.

A total of 105 subjects (fifteen men and ninety women; mean age 38.3 years) agreed to take part in the study. All subjects provided written informed consent to participate after the study procedures had been explained to them.

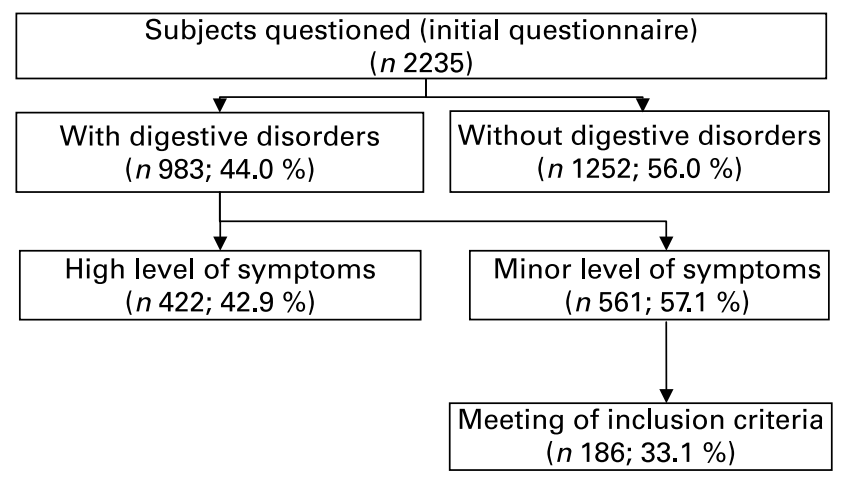

Fig. 1. Distribution of subjects (number and frequency) from initial respondents to the selected population meeting the inclusion criteria, i.e. presenting minor functional digestive disorders (according to the initial questionnaire based on the Rome II criteria ${ }^{23}$ : at least two symptoms experienced for at least 3 months over the previous 12 months, abdominal pain intensity score $\leq 5$ and global score $\leq 25$ ). Those with a high level of symptoms had a severity score for 'discomfort or abdominal pain' $>5$, or total severity score $>25$, or frequency of digestive disorders $>$ once a week, or number of symptoms $>5$.
The study was approved by the ethics committee of SaintGermain-en-Laye (France, no. 03 046) and was performed in accordance with the guidelines of the International Conference on Harmonisation of Technical Requirements for Registration of Pharmaceuticals for Human Use and the principles laid down in the current version of the Declaration of Helsinki.

\section{Questionnaires}

Initial questionnaire. The prevalence and general frequency of digestive symptoms based on the Rome II criteria were recorded in the initial questionnaire ${ }^{1,23,24}$. Subjects were asked to indicate which symptoms they were presenting. For five of the symptoms (abdominal discomfort or pain; abdominal fullness, bloating or swelling; feeling of incomplete bowel movement; urgency, i.e. an imperious urge to pass stool; straining at stool), subjects also indicated intensity on a scale from 1 to 10 (10 being the maximum intensity level). The initial questionnaire was used for inclusion and then at the end of the study to determine changes in intensity of symptoms.

Consultation questionnaire. A questionnaire designed to assess the frequency of digestive symptoms and stool quality for the last 4 weeks preceding the study was given by the study doctor to subjects meeting all inclusion criteria. This questionnaire was given again at the end of the study to determine the effects of sc-FOS.

Functional digestive disorders quality of life questionnaire. The quality of life of subjects was assessed using the validated French language functional digestive disorders quality of life (FDDQL) questionnaire ${ }^{25}$. Subjects completed the FDDQL questionnaire alone on the day of inclusion (day 0) and on the last day of the study (day 43) and changes in individual item scores were calculated.

\section{Short-chain fructo-oligosaccharides studied}

The sc-FOS studied were FOS Actilight ${ }^{\circledR}$ 950P (Béghin Meiji, Marckolsheim, France), comprising $37 \pm 6 \%$ 1-kestose (GF2), $53 \pm 6 \%$ nystose (GF3) and $10 \pm 6 \% 1 \mathrm{~F}$ - $\beta$-fructofuranosyl nystose (GF4). The placebo consisted of a mixture of $50 \%$ microcrystalline sucrose 120 (Béghin-Say; Tereos, Lille, France) and $50 \%$ maltodextrin Glucidex ${ }^{\circledR}$ IT6 (Roquette, Lestrem, France).

\section{Experimental design}

This multicentre, double-blind, randomised, controlled study was performed in five study centres to assess the effects of regular sc-FOS consumption on the quality of life and digestive comfort of subjects with minor FBD.

A total of 105 volunteers were randomised to two groups consuming either $5 \mathrm{~g}$ sc-FOS/d or $5 \mathrm{~g}$ placebo/d over a 6-week period (Fig. 2). Subjects were instructed not to change their eating habits; in order to check normal consumption of pre- and probiotics during the experimental period, they were asked on day 0 to evaluate their intake of foods containing pre- and probiotics or enriched in fibres such as some yoghurts, milk, sweets and biscuits.

Treatments were allocated in the form of two packets containing either $2.5 \mathrm{~g} \mathrm{sc}-\mathrm{FOS}$ or a blend of $1.25 \mathrm{~g}$ maltodextrin 


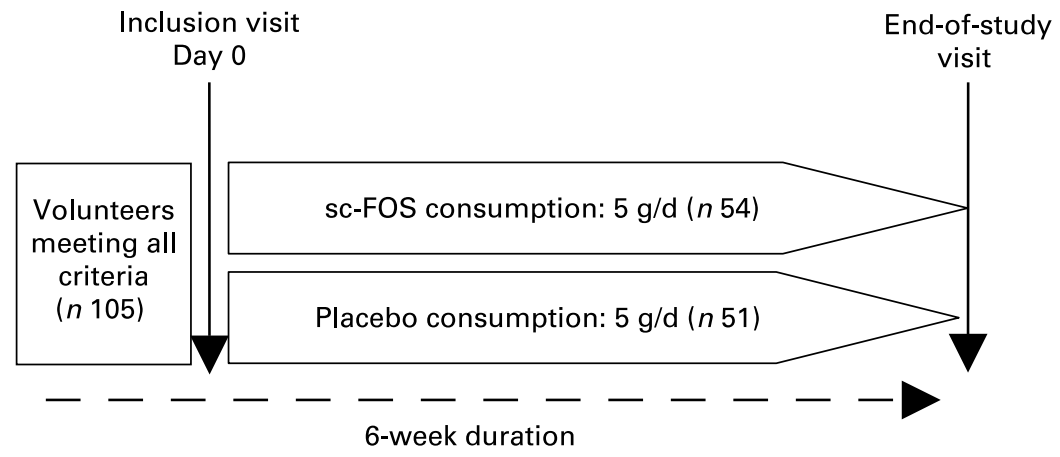

Fig. 2. Study design. sc-FOS, short-chain fructo-oligosaccharides.

and $1.25 \mathrm{~g}$ sucrose (tolerance $\pm 4 \%$ ), depending on the randomisation group. Two packets per $d$ were to be consumed, one at breakfast and one at dinner, either sprinkled over a dessert or diluted in a drink.

Compliance was checked using a form on which subjects kept a daily record of the number of packets consumed and the time of intake. All unused packets were to be returned by the subjects to the investigators at the end of the study.

\section{Statistics}

All statistical analyses were conducted using the SAS statistical program (version 8.2; SAS Institute Inc., Cary, NC, USA). All tests comparing the two groups (sc-FOS $v$. placebo) were two-tailed with type 1 error set at $0 \cdot 05$, taking into account the two-arm parallel design.

Qualitative variables were expressed in terms of degree and percentage. Both groups were compared for non-ordered qualitative variables using a $\chi^{2}$ test, or Fisher's exact test where size was too small $(<5)$. For ordered qualitative variables, both groups were compared using the WilcoxonMann-Whitney rank-sum test. Quantitative variables were expressed in terms of mean values, standard deviations and ranges. Depending on the results of the normality test (Shapiro-Wilk), the two groups were compared using a Student or Wilcoxon-Mann-Whitney rank-sum test.

Efficacy analysis. Changes in score between days 0 and 43 for each of the eight FDDQL questionnaire items were compared between the two groups using Student's test. The eight scores were summed and the global scores for days 0 and 43 were compared using Student's test. The intensity and frequency of symptoms as well as change in these parameters were also compared between the two groups using a Wilcoxon-Mann-Whitney test. Subject satisfaction was analysed using a $\chi^{2}$ test or Fisher's exact test.

Safety analysis. A global analysis was performed for the observed frequencies and the intensity of symptoms occurring during the treatment period.

\section{Results}

Step 1

A total of 2235 subjects completed the initial questionnaire. Age ranged from 16 to 75 years (age $36 \cdot 8$ (SD 10.9) years), and $75.7 \%$ of subjects were women. Of these, 983 subjects were presenting digestive disorders, $57.1 \%$ of whom had minor symptoms (i.e. $25.1 \%$ of subjects questioned). According to the symptoms reported, $36.9 \%$ of all subjects questioned presented abdominal discomfort (women, $40.8 \%$; men, $24.3 \%$ ), $25.6 \%$ presented constipation (women, $28.9 \%$; men, $15.3 \%$ ) and $21.9 \%$ presented diarrhoea (women, $22.4 \%$; men, $20.3 \%$ ). Only 186 subjects, mainly presenting abdominal discomfort $(96.8 \%)$ or constipation $(79.6 \%)$, met all inclusion criteria during checks by the study doctors. Of the ten representative symptoms of FBD, the average number actually presented was 5.1 (SD 1.9), with a global mean intensity of 11.5 (SD 5.9).

Step 2

A total of 105 subjects agreed to participate in the study and were randomised to the sc-FOS (fifty-four subjects) and placebo (fifty-one subjects) groups (Fig. 2).

Characteristics at inclusion. Demographic factors were similar between both groups (Table 1). Women accounted respectively for 83.3 and $85.7 \%$ of subjects in the sc-FOS and placebo groups. The item scores and global score on the FDDQL questionnaire completed at inclusion were comparable for the two groups.

Treatment: compliance and concomitant medication. Treatment compliance was judged satisfactory when the product (two packets of treatment per d) was consumed as instructed throughout the study period (consumption for at least $30 \mathrm{~d}$, consumption of the entire daily dose for at least $27 \mathrm{~d}$ and no interruption in intake for more than 4 consecutive days). In terms of these criteria, no significant differences were found in treatment compliance between the two groups $(P=0.83)$. To qualify for inclusion in the per protocol analyses, the date of the final visit also had to be within $10 \mathrm{~d}$ of the theoretical date (i.e. between 43 and $53 \mathrm{~d}$ after the start of study product intake).

Compliance was good for fifty subjects (consumption during respectively 40.9 (SD 1.9) $\mathrm{d}$ in the sc-FOS group (twenty-four subjects) and 41.3 (SD 1.4) $\mathrm{d}$ in the placebo group (twenty-six subjects)), but less satisfactory for the other forty-seven subjects. Eight subjects (four in each group) dropped out before the final medical visit.

As regards concomitant medication, nine subjects took a treatment having a potential minor influence on FBD (respectively four and five subjects in the sc-FOS and placebo groups). 
Table 1. Characteristics of patients in the intent-to-treat group with baseline intensity of symptoms related to minor functional bowel disorders (FBD)

(Mean values and standard deviations)

\begin{tabular}{|c|c|c|c|c|c|}
\hline \multirow[b]{2}{*}{ Characteristic } & \multicolumn{2}{|c|}{$\begin{array}{l}\text { sc-FOS group } \\
\quad(n 48)\end{array}$} & \multicolumn{2}{|c|}{$\begin{array}{l}\text { Placebo group } \\
\quad(n 49)\end{array}$} & \multirow[b]{2}{*}{$P$} \\
\hline & Mean & SD & Mean & SD & \\
\hline Age (years) & 39.5 & $11 \cdot 9$ & $37 \cdot 6$ & $10 \cdot 9$ & 0.397 \\
\hline Age range (years) & \multicolumn{2}{|c|}{$20-59$} & \multicolumn{2}{|c|}{$20-55$} & \\
\hline Females $(n)$ & \multicolumn{2}{|c|}{40} & \multicolumn{2}{|c|}{42} & 0.746 \\
\hline Symptoms related to minor FBD $(n)^{\star}$ & $5 \cdot 6$ & 1.8 & 5.5 & $1 \cdot 8$ & 0.898 \\
\hline $\begin{array}{l}\text { Symptoms related to minor FBD range }(n)^{*} \\
\text { Intensity of symptoms related to minor FBD }\end{array}$ & \multicolumn{2}{|c|}{$2-9$} & \multicolumn{2}{|c|}{$2-10$} & \\
\hline Abdominal pain $\dagger$ & 3.6 & 1.8 & 3.4 & $2 \cdot 1$ & 0.566 \\
\hline Abdominal fullnesst & $3 \cdot 7$ & $2 \cdot 4$ & $4 \cdot 0$ & $2 \cdot 1$ & 0.528 \\
\hline Feeling of incomplete bowel movement $\dagger$ & 1.7 & $2 \cdot 4$ & 1.6 & $2 \cdot 2$ & 0.800 \\
\hline Urgency† & 1.8 & $2 \cdot 6$ & $2 \cdot 1$ & $2 \cdot 7$ & 0.628 \\
\hline Straining at stool $\dagger$ & 2.9 & $3 \cdot 1$ & $3 \cdot 1$ & $2 \cdot 9$ & 0.694 \\
\hline $\begin{array}{l}\text { Global intensity of symptoms } \\
\text { Item scores on FDDQL for day } 0 \text { questionnaire }\end{array}$ & $13 \cdot 4$ & $7 \cdot 0$ & $13 \cdot 7$ & $6 \cdot 9$ & 0.857 \\
\hline Activities $\ddagger$ & $80 \cdot 9$ & $14 \cdot 7$ & $80 \cdot 5$ & $17 \cdot 3$ & 0.723 \\
\hline Anxiety $\ddagger$ & $64 \cdot 3$ & 24.4 & $67 \cdot 3$ & $24 \cdot 1$ & 0.454 \\
\hline Dietł & $64 \cdot 2$ & $17 \cdot 2$ & 64.5 & $21 \cdot 7$ & 0.628 \\
\hline Sleepł & 78.5 & $18 \cdot 3$ & $71 \cdot 8$ & 20.9 & 0.125 \\
\hline Discomfort & $46 \cdot 1$ & $15 \cdot 2$ & $44 \cdot 2$ & 19.9 & 0.694 \\
\hline Coping with disease $\ddagger$ & 71.5 & 14.9 & $70 \cdot 0$ & $17 \cdot 2$ & 0.645 \\
\hline Control of diseaseł & $56 \cdot 7$ & 24.9 & 48.5 & $26 \cdot 3$ & 0.118 \\
\hline Impact of stress $\ddagger$ & $32 \cdot 8$ & 27.4 & $30 \cdot 8$ & $23 \cdot 8$ & 0.890 \\
\hline Global score on FDDQL for day 0 questionnaireł & $66 \cdot 0$ & $9 \cdot 4$ & $63 \cdot 8$ & $13 \cdot 8$ & 0.700 \\
\hline
\end{tabular}

Furthermore, the occurrence of gastroenteritis in one subject may have had a minor effect on FBD.

\section{Safety analysis}

In the ninety-seven subjects in the intent-to-treat group, twenty-seven adverse events were seen, concerning respectively eleven $(22.9 \%)$ and sixteen $(32.6 \%)$ subjects in the sc-FOS and placebo groups. Severity of these adverse events was distributed as follows: nine were reported as light (two under sc-FOS $v$. seven under placebo), fifteen as mild (seven sc-FOS $v$. eight placebo) and three as severe (two sc-FOS $v$. one placebo). Five adverse events comprised infectious diseases such as angina, bronchitis, sinusitis or gastroenteritis (two sc-FOS $v$. three placebo), ten comprised gastrointestinal symptoms such as diarrhoea, constipation, abdominal pain, vomiting or nausea (six sc-FOS $v$. four placebo), twelve comprised painful symptoms including headache or lower back pain (five sc-FOS $v$. seven placebo) and six comprised other symptoms (for example, anxiety, weight loss). Of the three adverse events reported as severe, respectively two (abdominal pain and nausea (same subject), spots on the chest, back and arms) and one (unwarranted anxiety) were seen in the sc-FOS and placebo groups. Two patients had symptoms diagnosed as linked to sc-FOS consumption (possible or probable association); these were diarrhoea, and abdominal pain and nausea (same subject). Eight subjects definitively stopped consuming the product after the occurrence of an adverse event.

\section{Change in symptom intensity (initial questionnaire)}

At the beginning of the study, the sc-FOS and placebo groups showed similar intensity of digestive disorders (sc-FOS, 3.6 (SD 1.8); placebo, 3.4 (SD 2.1); $P=0.565$ ). Sc-FOS ingestion for 6 weeks significantly reduced symptom intensity by $43.6 \%(-1.6$ (SD 2.1); $P=0.026$, FOS $v$. placebo); the placebo group experienced a $13.8 \%$ increase (see Fig. 3 and Table 2).

\section{Change in frequency of digestive disorders (consultation questionnaire)}

The frequency of digestive disorders was assessed over the 4 weeks before the start of the study and at the end of the study. Over the 4 weeks preceding the start of the study (day 0), the various symptoms of digestive disorders occurred once per week in both groups (per protocol population) (Table 3): 41.7 and $38.5 \%$ of subjects in the sc-FOS and placebo groups, respectively. On day 43, a reduced frequency was noted in the sc-FOS group, with $20.8 \%$ for the mixed items 'more than once per week' and 'every day', whereas the frequency in the placebo group remained higher, at $42.3 \%$ for the same mixed items. None of these changes were statistically significant.

At 6 weeks later, symptoms were experienced less frequently by $75.0 \%$ of subjects in the sc-FOS group $(29.2 \%$ much less frequently; $45.8 \%$ rather less frequently) compared with control subjects, $53.8 \%$ of whom experienced no change, as shown in Fig. $4(P=0.064)$. 


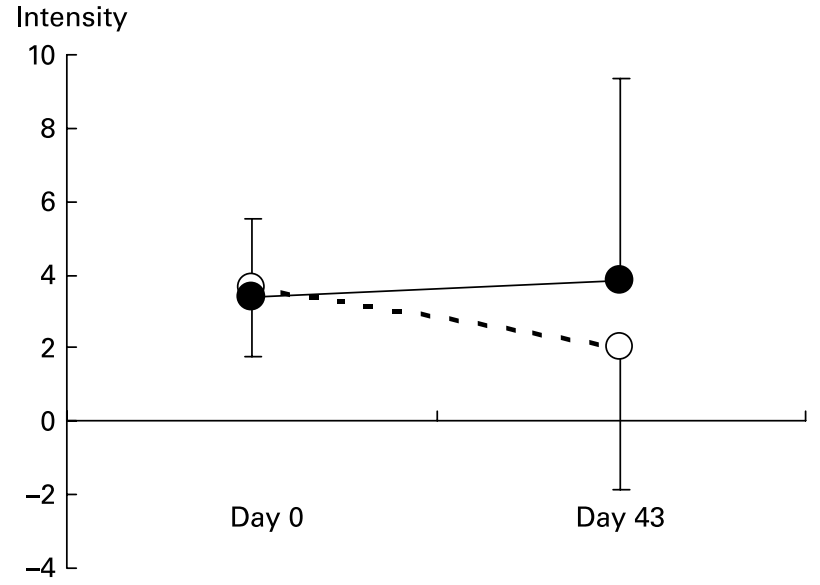

Time (d)

Fig. 3. Change in intensity of digestive disorders after 6 weeks' consumption of short-chain fructo-oligosaccharides (sc-FOS; O) or placebo $(\bullet)$ in the per protocol population. The intensity scores were assessed by subjects on a scale from 1 to 10 (maximum intensity). Values are means, with their standard deviations represented by vertical bars. At baseline, there was no difference between the groups (sc-FOS, 3.6 (SD 1.8); placebo, 3.4 (SD 2.1); Wilcoxon-Mann-Whitney rank-sum test, $P=0.565$ ). On day 43 , the mean intensity of digestive disorders between both groups was significantly different (sc-FOS, 2.1 (SD 3.9); placebo, 3.9 (SD 5.5); Wilcoxon-Mann-Whitney rank sum test, $P=0.026$ )

Change in quality of life after 6 weeks of short-chain fructooligosaccharide consumption

The FDDQL questionnaire item scores were compared between day 0 and day 43 for both groups (Table 4). As regards the per protocol population, the discomfort item scores appeared to have significantly increased in the sc-FOS group after 6 weeks of consumption of the study product compared with the placebo (sc-FOS, 20.1 (SD 14.2); placebo, 12.1 (SD 19.6); $P=0 \cdot 031$ ). The differences between the sc-FOS and placebo groups regarding the other item scores were not significant.

Change in quality of life was also analysed in terms of improvement (i.e. item score on day $43>$ day 0 ), worsening (i.e. item score on day $43<$ day 0 ) and no change in comfort

Table 2. Change in intensity of symptoms related to minor functional bowel disorders (FBD) in the per protocol population (day 43 - day 0 ) (Mean values and standard deviations)

\begin{tabular}{|c|c|c|c|c|c|}
\hline \multirow[b]{3}{*}{ Minor FBD symptoms } & \multicolumn{4}{|c|}{$\begin{array}{l}\text { Change in intensity } \\
\text { (day } 43 \text { - day } 0 \text { ) }\end{array}$} & \multirow[b]{3}{*}{$P$} \\
\hline & \multicolumn{2}{|c|}{$\begin{array}{c}\text { sc-FOS } \\
\text { group }(n 24)\end{array}$} & \multicolumn{2}{|c|}{$\begin{array}{c}\text { Placebo } \\
\text { group }(n 26)\end{array}$} & \\
\hline & Mean & SD & Mean & SD & \\
\hline Discomfort or abdominal pain & -1.6 & $2 \cdot 1$ & +0.5 & $3 \cdot 4$ & 0.026 \\
\hline $\begin{array}{l}\text { Abdominal fullness, bloating or } \\
\text { swelling }\end{array}$ & -0.7 & $2 \cdot 2$ & -0.4 & $2 \cdot 5$ & 0.828 \\
\hline $\begin{array}{l}\text { Feeling of incomplete bowel } \\
\text { movement }\end{array}$ & -0.4 & $2 \cdot 7$ & 0.0 & $2 \cdot 6$ & 0.491 \\
\hline Urgency & +0.2 & $3 \cdot 4$ & +0.4 & 2.9 & 1.000 \\
\hline Straining at stool & -1.4 & 3.7 & 0.0 & $2 \cdot 3$ & 0.211 \\
\hline
\end{tabular}

sc-FOS, short-chain fructo-oligosaccharides.
Table 3. Change in frequency of digestive disorders (\%) in the last 4 weeks before day 0 and day 43 in the per protocol population

\begin{tabular}{lccccr}
\hline & \multicolumn{2}{c}{$\begin{array}{c}\text { sc-FOS group } \\
(n \text { 24) }\end{array}$} & & \multicolumn{2}{c}{$\begin{array}{c}\text { Placebo group } \\
(n \text { 26) }\end{array}$} \\
\cline { 2 - 3 } \cline { 6 - 7 } Frequency (\%) & Day 0 & Day 43 & & Day 0 & Day 43 \\
\hline Less than once per month & 0 & 20.8 & & 0 & 15.4 \\
Once per month & 4.2 & 33.3 & & 3.8 & 7.7 \\
Once per week & 41.7 & 25.0 & & 38.5 & 30.8 \\
More than once per week & 45.8 & 8.3 & & 46.1 & 23.1 \\
Every day & 8.3 & 12.5 & & 11.5 & 19.2 \\
Data missing & 0 & 0 & & 0 & 3.8 \\
\hline
\end{tabular}

sc-FOS, short-chain fructo-oligosaccharides.

(i.e. item score on day $43=$ day 0 ). As shown in Fig. 5, digestive comfort tended to increase $(P=0.071)$ and daily activities were significantly improved $(P=0 \cdot 022)$. These increases respectively concerned 95.8 and $83.3 \%$ of subjects in the sc-FOS group.

Activity scores on day 43 also differed significantly between the sc-FOS and placebo groups (sc-FOS, 95.0 (SD 5.3); placebo, 82.7 (SD 19.7); $P=0 \cdot 011$ ). Subjects consuming sc-FOS were therefore less disturbed by their digestive symptoms in performance of their daily activities.

\section{Discussion}

The patients enrolled in the present study were screened using the Rome II criteria ${ }^{24}$. They are representative of the female population generally known to present $\mathrm{FBD}^{26}$. However, compared with previous FBD data for the French population ${ }^{6}$, the prevalence detected in the present study was lower (44 v. $61 \%$ ), which could be due to a lower mean age in the present study, as well as different socio-cultural makeup of the populations. This last factor is a consequence of the method of recruiting the subjects, who were mainly hospital staff members. Age, socio-economic status and culture are indeed recognised as important factors that can have a bearing on $\mathrm{FBD}^{26}$.

Beyond the prevalence of FBD, the study also provided information concerning the impact of FBD on quality of

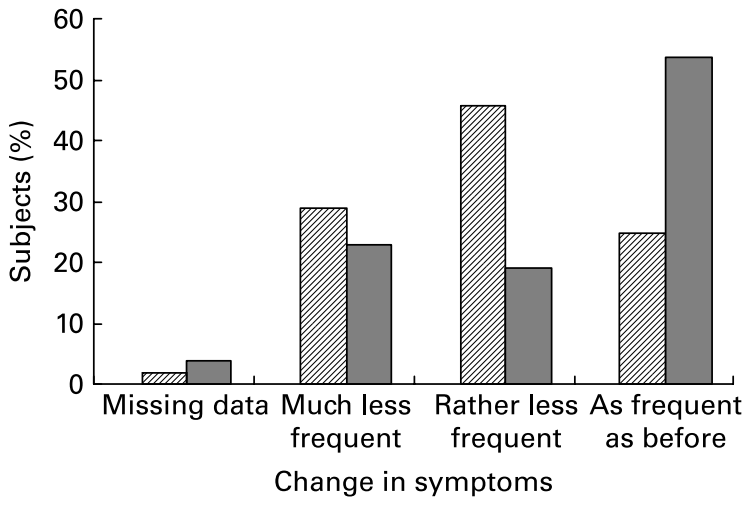

Fig. 4. Change in digestive disorder score after 6 weeks' consumption of short-chain fructo-oligosaccharides (sc-FOS; $\square$ ) or placebo $(\square)$ in the per protocol population. Subjects were questioned about their perception of the frequency of digestive disorders during the 4 weeks before the end of the study. A $x^{2}$ test was carried out to determine the difference between the scFOS and placebo groups $(P=0.064)$. 
Table 4. Change in quality of life between day 0 and day 43 in the per protocol population (expressed as change in item score) ${ }^{\star}$

(Mean values and standard deviations)

\begin{tabular}{|c|c|c|c|c|c|}
\hline \multirow[b]{3}{*}{ Item } & \multicolumn{4}{|c|}{$\begin{array}{l}\text { Change in item score } \\
\text { (day } 43-\text { day } 0)\end{array}$} & \multirow[b]{3}{*}{$P$} \\
\hline & \multicolumn{2}{|c|}{$\begin{array}{l}\text { Sc-FOS group } \\
(n 24)\end{array}$} & \multicolumn{2}{|c|}{$\begin{array}{l}\text { Placebo group } \\
\qquad(n 26)\end{array}$} & \\
\hline & Mean & SD & Mean & SD & \\
\hline Activities & $+10 \cdot 3$ & $10 \cdot 5$ & $+5 \cdot 0$ & $15 \cdot 2$ & 0.109 \\
\hline Anxiety & $+15 \cdot 3$ & $18 \cdot 5$ & $+6 \cdot 2$ & $18 \cdot 4$ & 0.134 \\
\hline Diet & $+10 \cdot 2$ & $17 \cdot 9$ & $+5 \cdot 6$ & $14 \cdot 0$ & 0.315 \\
\hline Sleep & +5.9 & $14 \cdot 6$ & $+14 \cdot 7$ & $17 \cdot 2$ & 0.057 \\
\hline Discomfort & $+20 \cdot 1$ & $14 \cdot 2$ & $+12 \cdot 1$ & $19 \cdot 6$ & 0.031 \\
\hline Coping with disease & $+2 \cdot 4$ & $12 \cdot 0$ & $+4 \cdot 3$ & $12 \cdot 1$ & 0.574 \\
\hline Control of disease & $+7 \cdot 6$ & $31 \cdot 7$ & $+13 \cdot 5$ & $26 \cdot 0$ & 0.350 \\
\hline Impact of stress & $+1 \cdot 7$ & $24 \cdot 3$ & +4.8 & 31.7 & 0.704 \\
\hline
\end{tabular}

sc-FOS, short-chain fructo-oligosaccharides.

${ }^{*}$ Measured with the functional digestive disorders quality of life questionnaire.

life. Contrary to previous studies ${ }^{2,27-30}$, a specific quality-oflife questionnaire devoted to functional digestive disorders was used to assess each patient's own evaluation of his or her health status ${ }^{25}$. This is currently the most relevant, valid and responsive questionnaire available to assess the impact of FBD status on quality of life as perceived by the patient. Other questionnaires, such as the 'medical outcomes study 36-item short form', the sickness impact profile, and the psychological general wellbeing scale, are generic instruments designed to compare health status scores among subjects with various diseases but do not focus on the specific impact of a

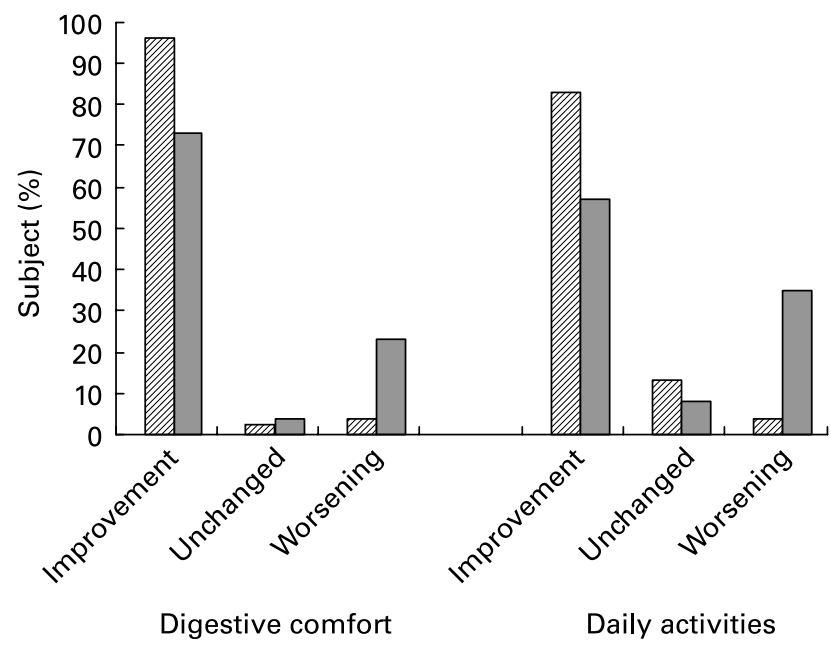

Change in symptoms

Fig. 5. Change in digestive comfort and degree of discomfort in daily activities after 6 weeks' consumption of short-chain fructo-oligosaccharides (sc-FOS; $\square$ ) or placebo ( $\square$ ) in the per protocol population. Change was defined as follows: improvement $=$ (item score on day $43>$ item score on day 0 ); worsening $=$ (item score on day $43<$ item score on day 0 ); unchanged $=($ item score on day $43=$ item score on day 0$)$, with a higher score being associated with superior quality of life. Change in the item 'daily activities' was seen to differ significantly between the sc-FOS and placebo groups (Fisher's exact test; $P=0.022$ ), whereas change in the item 'digestive comfort' was close to significance (Fisher's exact test; $P=0.071$ ). particular symptom on their quality of life. They were therefore less likely to detect small but clinically important changes induced by the treatment used during the present study ${ }^{31,32}$. For example, problems largely experienced by patients with irritable bowel syndrome such as abdominal pain or urgency would not be singled out by the above-mentioned questionnaires.

Furthermore, the present study is the first dealing with FBD to be carried out in a working population not undergoing medical treatment. To date, no randomised, placebo-controlled clinical trials have been performed introducing a dietary ingredient for the treatment of minor FBD symptoms and using relevant evaluation methods to quantify the results. For subjects presenting these symptoms, which while not severe cause discomfort in all daily activities, dietary change could have a significant impact on wellbeing as well as working capacity, and may thus have potential benefits for healthcare spending ${ }^{2,29,30}$.

A recent study showed that sc-FOS are bifidogenic and well tolerated at doses ranging from 2.5 to $10 \mathrm{~g} / \mathrm{d}$ with a doseresponse relationship in healthy volunteers ${ }^{33}$. Studies with higher dosages of sc-FOS did not show any further increase in Bifidobacteria count but excessive flatus occurred in some cases ${ }^{14}$. In another threshold study evaluating symptomatic response to varying levels of sc-FOS ingested regularly by fourteen healthy volunteers, excessive flatus and borborygmus were recorded by about $10 \%$ of volunteers at $10 \mathrm{~g} / \mathrm{d}^{34}$. We therefore chose to test a $5 \mathrm{~g} / \mathrm{d}$ dose rather than $10 \mathrm{~g} / \mathrm{d}$ in our trial in subjects with FBD, particularly as subjects with irritable bowel syndrome are more sensitive and could present more pronounced gastrointestinal side effects than healthy subjects for a given dose ${ }^{35}$.

An improvement in digestive comfort (close to significance) and in performance of daily activities (significant) was observed under sc-FOS compared with placebo. Other items related to quality of life (anxiety, diet, sleep, control of disease, coping with disease and stress) showed no significant change compared with placebo. No significant change in intensity of symptoms was noticed with sc-FOS consumption except for digestive disorders and abdominal pain, which were significantly lower compared with placebo. In the present study, the placebo effect appeared remarkably high. The influence of psychological and environmental factors on these symptoms ${ }^{6}$ is well known, but this could also explain why several statistical tendencies were obtained rather than solid statistical effects.

This double-blind, placebo-controlled study was carried out to assess the effect of regular and moderate sc-FOS consumption on the quality of life of subjects presenting untreated minor FBD. It was initially assumed that these dietary fibres could reduce symptoms linked with FBD and therefore improve the quality of life of such subjects. Finally, we showed that 6 weeks' consumption of $5 \mathrm{~g}$ sc-FOS/d led to a significant decrease in the intensity of digestive disorders. Improvement was also noted in digestive comfort and in daily activities. On the basis of these findings, we conclude that regular consumption of $5 \mathrm{~g}$ sc-FOS/d may improve digestive comfort in subjects with minor FBD, thereby improving quality of life as well as social performance.

It would also be useful to study the effect of sc-FOS consumption on irritable bowel syndrome, a particular form of functional bowel disorder. Referring to the Rome III 
criteria ${ }^{36}$, irritable bowel syndrome is in fact characterised by abdominal pain and discomfort associated with defecation disorders. Throughout the world, about $10-20 \%$ of adults and adolescents have symptoms consistent with irritable bowel syndrome $^{37}$, which is slightly less than the level found in the subjects initially questioned in the present study (Fig. 1); these symptoms are frequently associated with impaired quality of life ${ }^{38,39}$ and high healthcare costs ${ }^{40}$. The impact of sc-FOS on Crohn's disease is another interesting area for investigation. A recent study proved that 3 weeks' consumption of $15 \mathrm{~g}$ fructans/d reduces the activity of Crohn's disease $^{41}$. Increased levels of faecal bifidobacteria, modification of mucosal dendritic cell function and production of butyrate with its anti-inflammatory properties could all be involved in this effect ${ }^{42,43}$. Further justification for such studies lies in the fact that no efficient treatment is yet available despite a prevalence of $25-150$ per 100000 worldwide.

\section{Acknowledgements}

The present study was supported by a grant from the health and nutrition group, Béghin Meiji (Marckolsheim, France).

\section{References}

1. Thompson WG, Longstreth GF, Drossman DA, Heaton KW, Irvine EJ \& Müller-Lissner SA (1999) Functional bowel disorders and functional abdominal pain. Gut 45, Suppl. 2, II43-II47.

2. Drossman D, Li Z \& Andruzzi E (1993) Householder survey of functional gastrointestinal disorders. Prevalence, socio-demography, and health impact. Dig Dis Sci 38, 1569-1580.

3. Talley N, Weaver AL \& Zinsmeister AR (1995) Impact of functional dyspepsia on quality of life. Dig Dis Sci 40, 584-589.

4. Kettel J, Jones R \& Lydeard S (1992) Reasons for consultation in irritable bowel syndrome: symptoms and patients characteristics. Br J Gen Pract 42, 459-461.

5. Camilleri M \& Choi M (1997) Review Article: irritable bowel syndrome. Aliment Pharmacol Ther 11, 3-15.

6. Frexinos $\mathrm{J}$, Denis $\mathrm{P}$, Allemand $\mathrm{H}$, Allouche $\mathrm{S}$, Los $\mathrm{F} \&$ Bonnelye G (1998) Descriptive study of digestive functional symptoms in the French general population. Gastroenterol Clin Biol 22, 785-791.

7. Sainsbury A \& Heatley RV (2005) Review article: psychosocial factors in the quality of life of patients with inflammatory bowel disease. Aliment Pharmacol Ther 21, 499-508.

8. Thompson WG, Heaton KW, Smyth GS \& Smyth C (1997) Irritable bowel syndrome: the view from general practice. Eur J Gastroenterol Hepatol 9, 689-692.

9. Dapoigny M, Dyard F, Grimaud J, Guyot P \& van Ganse E (2003) Troubles fonctionnels intestinaux et consommation de soins. Etude observationnelle en gastroentérologie libérale (Irritable bowel syndrome and healthcare consumption. An observational study in private gastroenterology). Gastroenterol Clin Biol 27, 265-271.

10. Talley N, Gabriel S, Harmsen W, Zinsmeister A \& Evans RW (1995) Medical costs in community subjects with irritable bowel syndrome. Gastroenterology 109, 1736-1741.

11. Maxion-Bergemann S, Thielecke F, Abel F \& Bergemann R (2006) Costs of irritable bowel syndrome in the UK and US. Pharmacoeconomics 24, 21-37.

12. Molis C, Flourié B, Ouarne F, Gailing MF, Lartigue S, Guibert A, Bornet F \& Galmiche JP (1996) Digestion, excretion, and energy value of fructooligosaccharides in healthy humans. $A m$ J Clin Nutr 64, 324-328.

13. Bouhnik Y, Raskine L, Simoneau G, Vicaut E, Neut C, Flourié B, Brouns F \& Bornet F (2004) The capacity of non-digestible carbohydrates to stimulate fecal bifidobacteria in healthy humans: a double-blind, randomized, placebo controlled, parallel group, dose-response relation study. Am J Clin Nutr 80, $1658-1664$.

14. Bouhnik Y, Vahedi K, Achour L, Attar A, Salfati J, Pochart P, Marteau P, Flourié B, Bornet F \& Rambaud JC (1999) Shortchain fructo-oligosaccharide administration dose-dependently increases fecal bifidobacteria in healthy humans. J Nutr 129, $113-116$.

15. Buddington RK, Williams CH, Chen SC \& Witherly SA (1996) Dietary supplement of neosugar alters the fecal flora and decreases activities of some reductive enzymes in human subjects. Am J Clin Nutr 63, 709-716.

16. Gibson GR \& Roberfroid MB (1995) Dietary modulation of the human colonic microbiota: introducing the concept of prebiotics. J Nutr 125, 1401-1412.

17. Hidaka H (1986) Effects of fructo-oligosaccharides on intestinal flora and human health. Microflora 5, 37-50.

18. Berggren AM, Björck IM, Nyman EM \& Eggum BO (1993) Short chain fatty acid content and $\mathrm{pH}$ in caecum of rats given various source of carbohydrates. J Sci Food Agri 63, 397-406.

19. Nyman M (2002) Fermentation and bulking capacity of indigestible carbohydrates: the case of inulin and oligofructose. $\mathrm{Br} \mathrm{J}$ Nutr 87, Suppl. 2, S163-S168.

20. Fich A, Phillips SF, Hakim NS, Brown ML \& Zinsmeister AR (1998) Stimulation of ileal emptying by short-chain fatty acids. Dig Dis Sci 34, 1516-1520.

21. Cherbut C, Aube AC, Blottière HM, Pacaud P, Scarpignato C \& Galmiche JP (1996) In vitro contractile effects of short-chain fatty acids in the rat terminal ileum. Gut 38, 53-58.

22. Cherbut C, Aube AC, Blottière HM \& Galmiche JP (1997) Effects of short-chain fatty acids on gastrointestinal motility. Scand J Gastroenterol Suppl 222, 58-61.

23. Drossman DA (1999) The functional gastrointestinal disorders and the Rome II process. Gut 45, Suppl. 2, II1-II5.

24. Drossman DA (2000) The functional gastrointestinal disorders, their diagnosis, and the Rome II process. In Rome II. The Functional Gastrointestinal Disorders: Diagnosis, Pathophysiology and Treatment: A Multinational Consensus, 2nd ed., pp. 1-36 [DA Drossman, E Corazziari, NJ Talley, WG Thompson and WE Whitehead, editors]. McLean, VA: Degnon Associates.

25. Chassany O, Marquis P, Scherrer B, Read N, Finger T, Bergmann J, Fraitag B, Geneve J \& Caulin C (1999) Validation of a specific quality of life questionnaire for functional digestive disorders. Gut 4, 527-533.

26. Chang L, Toner BB, Fukudo S, Guthrie E, Locke GR, Norton NJ \& Sperber AD (2006) Gender, age, society, culture, and the patient's perspective in the functional gastrointestinal disorders. Gastroenterology 130, 1435-1446.

27. Si JM, Yu YC, Fan YJ \& Chen SJ (2004) Intestinal microecology and quality of life in irritable bowel syndrome patients. World J Gastroenterol 10, 1802-1805.

28. Bushnell DM, Martin ML, Ricci JF \& Bracco A (2006) Performance of the EQ-5D in patients with irritable bowel syndrome. Value Health 9, 90-97.

29. Wilhelmsen I (1995) Quality of life in upper gastrointestinal disorders. Scand J Gastroenterol 211, 21-25.

30. Talley NJ, Fett SL \& Zinsmeister AR (1994) Gastrointestinal tract symptoms and self-reported abuse: a population-based study. Gastroenterology 107, 1040-1049.

31. Wiklund I, Dimenäs E \& Wahl M (1990) Factors of importance when evaluating quality of life in clinical trials. Control Clin Trials 11, 169-179. 
32. Patrick DL \& Deyo RA (1989) Generic and disease-specific measures in assessing health status and quality of life. Med Care 27, Suppl. 3, S217-S232.

33. Bouhnik Y, Raskine L, Simoneau G, Paineau D \& Bornet F (2006) The capacity of short-chain fructo-oligosaccharides to stimulate faecal bifidobacteria: a dose-response relationship study in healthy humans. Nutr $J \mathbf{5}, 8$.

34. Briet F, Achour L, Flourié B, Beaugerie L, Pellier P, Franchisseur C, Bornet F \& Rambaud JC (1995) Symptomatic response to varying levels of fructo-oligosaccharides consumed occasionally or regularly. Eur J Clin Nutr 49, 501-507.

35. Rumessen JJ \& Gudmand-Hoyer E (1988) Functional bowel disease: malabsorption and abdominal distress after ingestion of fructose, sorbitol, and fructose-sorbitol mixtures. Gastroenterology 95, 694-700.

36. Longstreth G, Thompson W, Chey WD, Houghton LA, Mearin F \& Spiller RC (2006) Functional bowel disorders. Gastroenterology 130, $1480-1491$.

37. Gwee KA (2005) Irritable bowel syndrome in developing countries - a disorder of civilization or colonization? Neurogastroenterol Motil 1, 317-324.

38. Wilson A, Longstreth G, Knight K, Wong J, Wade S, Chiou C, Barghout V, Frech F \& Ofman J (2004) Quality of life of managed care patients with irritable bowel syndrome. Manag Care Interface 17, 24-28.

39. Amouretti M, Le Pen C, Gaudin A-F, Bommelaer G, Frexinos J, Ruszniewski P, Poynard T, Maurel F, Priol G \& El Hasnaoui A (2006) Impact of irritable bowel syndrome (IBS) on health-related quality of life (HRQOL). Gastroenterol Clin Biol 30, 241-246.

40. Longstreth G, Wilson A, Knight K, Wong J, Chiou C, Barghout V, Frech F \& Ofman J (2003) Irritable bowel syndrome, health care use, and costs: a U.S. managed care perspective. Am J Gastroenterol 98, 600-607.

41. Lindsay JO, Whelan K, Stagg AJ, Gobin P, Al-Hassi HO, Rayment N, Kamm MA, Knight SC \& Forbes A (2006) Clinical, microbiological, and immunological effects of fructo-oligosaccharide in patients with Crohn's disease. Gut 55, 348-355.

42. Di Sabatino A, Morera R, Ciccocioppo R, Cazzola P, Gotti S, Tinozzi FP, Tinozzi S \& Corazza GR (2005) Oral butyrate for mildly to moderately activate Crohn's disease. Aliment Pharmacol Ther 22, 789-794.

43. Segain JP, Raingeard de la Blétière D, Bourreille A, Leray V, Gervois N, Rosales C, Ferrier L, Bonnet C, Blottiere HM \& Galmiche JP (2000) Butyrate inhibits inflammatory responses through NF $\kappa \mathrm{B}$ inhibition: implications for Crohn's disease. Gut 47, 397-403. 